\title{
Product Pre-1938 Indicator
}

National Cancer Institute

\section{Source}

National Cancer Institute. Product Pre-1938 Indicator. NCI Thesaurus. Code C94030.

Specifies whether the product qualifies under the 1938 Grandfather Clause, contained in section 20l(p)(I) of the U.S. Federal Food, Drug and Cosmetic Act. 